\title{
ANTAGONISMO Y SORORIDAD EN DOS CUENTOS DEL CARIBE HISPANO
}

\author{
ANTAGONISM AND SORORITY IN TWO SHORT STORIES \\ OF THE HISPANIC CARIBBEAN
}

\author{
Mercedes Ortega González-Rubio \\ Universidad del Norte. Colombia \\ mercedesortega@uninorte.edu.co
}

\begin{abstract}
Resumen: En el artículo, la relación entre los personajes femeninos de los cuentos "Cuando las mujeres quieren a los hombres" (Rosario Ferré) y "Las fiebres del Miramar" (Marvel Moreno) es estudiada teniendo en cuenta los factores que conforman sus identidades (raza, clase, género). Se proponen dos interpretaciones: primero, se entiende que hay un enfrentamiento entre ellos, consecuencia del pensamiento masculinista hegemónico según el cual las mujeres deben tener identidades fijas: esposas o amantes; segundo, la interacción entre ellas es vista como un avance positivo en su emancipación y en la construcción de subjetividades que no responden ciegamente a las imposiciones de la heteronormatividad.
\end{abstract}

Palabras clave: Antagonismo, sororidad, Caribe, cuento, escritura de mujeres, feminismo.

\begin{abstract}
In this paper, the relationship between the female characters of the short stories "Cuando las mujeres quieren a los hombres" (Rosario Ferré) and "Las fiebres del Miramar" (Marvel Moreno) is studied regarding the factors conforming their identities (race, class and gender). I propose two interpretations: first, there is a confrontation between these characters, consequence of masculinist hegemonic thought according to which they have fix identities: wives or lovers; second, the interaction between them can be seen as a progress in their emancipation and in the construction of subjectivities not responding blindly to the impositions of heteronormativity.
\end{abstract}

Keywords: Antagonism, sorority, Caribbean, short story, women's writing, feminism.

Recibido: 16.06.2017. Aceptado: 10.05.2018. 


\section{Introducción}

$\mathrm{H}^{\mathrm{N}}$ EL CARIBE colombiano sigue muy vigente el imaginario del antagonismo Centre las mujeres. En octubre de 2014 ocurrió un episodio que refleja esta situación, incidente que acaparó la atención de los medios de comunicación de masas y trascendió a la cultura popular, a través de entrevistas en noticieros, memes, disfraces de carnaval, slogans en camisetas, parodias y canciones. En un video subido al sitio web YouTube, dos mujeres que van en una lancha de pasajeros en el río Magdalena se agreden verbalmente, debido a que ambas han tenido relaciones sexuales y afectivas con el mismo hombre. En las imágenes, la única que puede observarse claramente, en primer plano, es la anterior pareja, con nombre propio (María Niño); la actual pareja aparece en la lejanía y su voz apenas se escucha. María Niño alega que mientras ella viva, la otra no podrá ser feliz porque ella es "su tormento". Sin conocer los pormenores de la historia, la audiencia la identificó como la amante, que humilla a la "mujer oficial" y se defiende de sus insultos, esa que normalmente se esconde pero que, al mismo tiempo, todos conocen. El Caribe colombiano se reconoció de forma inmediata en esta mujer sin pudores, pícara "de lengua resuelta que no se deja pisotear" (Gontovnik, 2014), que no tiene vergüenza en aceptar un rol del que, por el contrario, parece sentirse orgullosa. Podría entenderse esta simpatía por la acción que ejecuta María Niño como un rasgo de nuestra cultura carnavalizada en la que la "esposa aburrida" no llama la atención, pues no tiene nada que mostrar, mientras que la amante con "sabrosura" (como ella misma se define) es celebrada.

Este caso es una muestra actual de la oposición entre mujeres, que también vemos representada en dos cuentos escritos por autoras del Caribe: "Las fiebres del Miramar" de la colombiana Marvel Moreno ${ }^{1}$ (Barranquilla, 1939 - París, 1995) y "Cuando las mujeres quieren a los hombres" de la puertorriqueña Rosario Ferré (Ponce, 1938 - San Juan, 2016)². En el primero se

\footnotetext{
${ }^{1}$ Este artículo hace parte de la investigación titulada Representaciones de lo femenino en la obra de Marvel Moreno (2016-2017), financiada por la Universidad del Norte, Barranquilla (Colombia).

${ }^{2}$ El relato de Moreno fue originalmente publicado de manera individual en 1995 en Lecturas dominicales de El Tiempo de Colombia, y en la revista Quimera de Barcelona, luego de la muerte de la autora; más adelante se publicó en Cuentos completos (2001), edición que utilizaremos para las citas. En cuanto al cuento de Ferré, se publicó inicialmente en 1976 y citaremos esa versión.
} 
muestra a una pareja de recién casados, el norteamericano Nick y su esposa Liliana, barranquillera y de familia burguesa, quienes pasan su luna de miel en El Miramar, un balneario del Caribe colombiano. Nick comienza a tener un affaire con Piedad, la mesera del lugar. Liliana, al darse cuenta, hace que la despidan y trae a su padre para que le sirva de chaperón, pero el amorío continúa. Aparece entonces el hermano de Piedad, Raúl, violador y maleante que quiere sacar provecho de la situación del "gringo". Este, al ver su carrera política amenazada por el escándalo, termina la relación con Piedad y la "indemniza" con dinero; vuelve con su esposa, quien ahora es verdaderamente feliz, porque en su nueva vida de pareja su esposo evidencia lo aprendido en el plano sexual con su amante. Al poco tiempo, Raúl, quien le ha robado el dinero a su hermana, decide seducir a Liliana y se cuela en el balneario con tal fin, pero ella lo rechaza. Al día siguiente, él va a fisgonearla por un agujero mientras esta se desviste en una de las casillas del lugar, pero ella le pincha un ojo con el alfiler de su sombrero, dejándolo tuerto y adolorido.

En "Cuando las mujeres quieren a los hombres" de Rosario Ferré, también aparecen dos mujeres enfrentadas por un hombre, Ambrosio. Isabel Luberza, la esposa digna, debe soportar por años la infidelidad de su marido con Isabel la Negra, quien además es prostituta 3 y que, para complacer al hombre, tiene relaciones sexuales con los hijos de sus pudientes amigos. Cada una sabe de la existencia de la otra, compiten y se envidian. Antes de morir, Ambrosio resuelve dividir la herencia entre las dos. Isabel Luberza se encierra en su caserón debido al escándalo producido por la decisión de su esposo, mientras Isabel la Negra abre un burdel que cada día se vuelve más popular. Luego de muchos años, la ex amante decide visitar a la viuda oficial con el fin de reclamar la parte de la casa que le corresponde, poner

\footnotetext{
${ }^{3}$ Como lo menciona Simonovis (2010), "Isabel 'La Negra', Isabel Luberza e Isabel Luberza Oppenheimer son algunos de los nombres con los que se conoce a esta famosa prostituta de Ponce" (66). Además de Ferré, otros dos escritores puertorriqueños han escrito sobre ella: Manuel Ramos Otero en el relato "La última plena que bailó Luberza" (1979), y Mayra Santos-Febres en la novela Nuestra Señora de la Noche (2006). Así que en la historia real que inspira la creación del personaje de Ferré, Isabel Luberza e Isabel La Negra son la misma persona: "De Isabel Luberza es muy poco lo que se sabe, aparte de que nació en el barrio de San Antón durante la primera década del siglo XX. Fue la dueña de un prostíbulo en Ponce, el Elizabeth's Dancing Club, el cual se convirtió en una de las atracciones principales de la época, puesto que su clientela contaba con hombres de distintas clases sociales, incluyendo políticos y soldados del ejército norteamericano. Luberza fue asesinada en 1974 y el misterio que rodea su muerte aún no ha sido esclarecido" (66).
} 
allí su negocio e incluso proponerle que sea su socia. El final del cuento es fantástico, pues ambas mujeres parecen fundirse en una sola, sin que quede del todo claro si una muere y la otra sobrevive4.

Este artículo se centra en las relaciones entre los personajes femeninos de estos dos cuentos. Considero que la visión de la identidad femenina que se presenta en ellos puede ser comprendida no como si se tratara de dos mujeres diferentes, sino mejor como las diversas caras de una misma subjetividad, la femenina, que está fragmentada y cuyas secciones a veces son complementarias y otras contradictorias. Analizaré la interacción entre los dos tipos de personajes femeninos, que pueden ser inicialmente descritos en estos términos: por un lado están las esposas habitantes blancas y ricas de la costa Caribe, y por otro las amantes, también caribeñas pero de clase baja y negras. Esta definición prosaica se hace a propósito, con el fin de resaltar que los convencionalismos, que pasan normalmente desapercibidos, son los que más prejuicios portan. Justamente, mi intención es la de reflexionar acerca de los conceptos de feminidad, clase, negritud y sexualidad que los cuentos de Moreno y Ferré despliegan.

Desde el principio surgen preguntas acerca de lo que hace iguales a las mujeres representadas en los cuentos y lo que las diferencia. Por un lado, ser identificadas como pertenecientes al sexo femenino las convierte en víctimas de la misma dominación, pero su vinculación a diferentes racializaciones y clases sociales las coloca en posiciones jerárquicas. Por otro lado, como mujeres habitantes de las costas caribeñas, comparten un mismo imaginario cultural, pero el estar ubicadas en lados opuestos de la balanza social, étnica y económica necesariamente las aleja y las enfrenta. A su vez, podemos observar que los papeles que las definen (esposa/amante) merecen un examen más profundo que tenga en cuenta ya no el vínculo con el hombre, sino entre ellas, relación que oscila entre la enemistad y la solidaridad, el odio y el deseo. Este último punto llama de manera particular nuestra atención pues en él confluyen las demás particularidades identitarias, además de que prevemos que es precisamente allí donde los relatos plantean una propuesta novedosa y compleja.

\footnotetext{
${ }^{4}$ Recordemos que lo fantástico radica en la duda entre la explicación racional y la irracional de un fenómeno extraño (Todorov, 2001).
} 


\section{El antagonismo}

Estos cuentos traen al primer plano un enfrentamiento entre lo aceptable y lo inadmisible, lo decente y lo impúdico. Si bien el papel de las mujeres en las sociedades patriarcales ha estado adscrito tradicionalmente al ámbito de lo privado, a las esposas se les asocia con un rol social y familiar, mientras que a las amantes se las reduce a satisfacer el deseo sexual de los hombres. Los personajes femeninos se sienten incompletos, pues no pueden asumir las dos actuaciones o los dos polos del eterno femenino - la virgen y la puta-, pero cada uno defiende rabiosamente el estereotipo que se les asigna. De un lado, las esposas descargan sobre las amantes la rabia que no son capaces de mostrar frente a los maridos; del otro, las amantes se cobran en la cama las ofensas que han recibido de sus enemigas. Ambas se hacen daño mutuamente y no son solidarias entre sí.

Las mujeres son siempre un cuerpo para ser usado por los hombres: tanto amantes como esposas son utilizadas por ellos con un propósito, aunque este sea diferente. Las esposas sirven para la respetabilidad social y la procreación, mientras que las amantes son aprovechadas para el placer sexual, en la clandestinidad. En "Las fiebres del Miramar”, por ejemplo, Liliana sabe que Nick, aspirante a senador, la necesita para representar a la "esposa irreprochable, capaz de recibir a lo más granado de la sociedad" (361). La misma dicotomía aplica para "Cuando las mujeres quieren a los hombres”, pues Isabel Luberza es consciente de la actuación que se le impone, la de madresposa:

He cumplido mi deber, he protegido tu fortuna, [...] he servido para algo que no fue ser esta mañana el estropajo donde te limpiaste los pies, donde te restregaste el pene bien rápido para tener un orgasmo casi puro, tan limpio como el de una mariposa, [...] un orgasmo fértil, que depositó en mi vientre la semilla sagrada que llevará tu nombre, [...] he sido tu mujercita querida como debe ser, económica y limpia pero sobre todo un dechado de honestidad, tabernáculo tranquilo de tu pene rosado [...] (38-39).

Según Marcela Lagarde (2003), todas las mujeres son madresposas por definición, lo que consiste "en vivir de acuerdo con las normas que expresan su ser - para y de otros-, realizar actividades de reproducción y tener relaciones de servidumbre voluntaria, tanto con el deber encarnado en los otros, 
como con el poder en sus más variadas manifestaciones" (363). Lagarde afirma que tanto en la cultura como en la conciencia de los sujetos -sobre todo en las mismas mujeres- la conyugalidad no pasa "por la realización del erotismo conyugal dominante" (364); así, "si no ocurre como la norma lo enuncia, no son percibidas. [...] No existe conceptualmente la posibilidad de relaciones con motivaciones, funciones y contenidos diversos polivalentes, aunque sucedan en la realidad social" (364-365). Así que ser objeto de erotismo no hace parte del perfil normativo de esposa, pero en la práctica estas sí cumplen con esta función ${ }^{5}$.

En el pasaje anteriormente citado del cuento de Ferré, se observa claramente cómo, a pesar de que el rol que impera para Isabel Luberza es el de la madre y ama de casa, ella cumple con sus deberes sexuales para con Ambrosio, quien saca placer de ese objeto que es ella para él. Así que se echa abajo la idea de que el hombre no goza con la esposa, así sea que este placer esté asociado con pureza y la sacralidad, diferente sin duda del que experimenta con la amante.

En las sociedades patriarcales, las amantes son las "especializadas en las relaciones eróticas" (Lagarde, 2001: 52): constituyen un "símbolo asociado al eros, a la pasión, a la aventura, también a la diversión. [...] Se espera que sean buena compañía, disponibles, ilimitadas, dispuestas a la superficialidad, a la frivolidad" (52). Tal es el papel que cumple Isabel la Negra, a lo que hay que agregar que ella es, además, prostituta: "la mujer social y culturalmente estructurada en torno a su cuerpo erótico" (Lagarde, 2003: 563). Se trata de la cosificación total de un sujeto, como lo vemos en la descripción de este personaje: "Isabel [...] girando su vientre de giroscopio en círculos de bengala dentro de los ojos de los hombres, meneando para ellos, desde tiempos inmemoriales, su crica multitudinaria y su culo monumental" (25-26) ${ }^{6}$. Para ellos, ella no es una persona sino vientre, crica, culo. Además, se trata de un

${ }^{5}$ En un libro posterior, Lagarde (2001) incluye la dimensión sexual más claramente en el perfil de la madresposa: "Como resultado del modelo burgués, las madresposas deben asumirse -aunque de forma ambivalente- como seres de la sexualidad. Educadas con prohibiciones, tabúes, con pecados sexuales por todas partes, tienen que aprender al mismo tiempo a satisfacer necesidades sexuales" (51).

${ }^{6}$ Obsérvese aquí la intertextualidad con la Mamá Grande, con sus tetas matriarcales y nalgas monumentales, en el cuento Los funerales de la Mamá Grande de Gabriel García Márquez; esto sugiere otro análisis comparativo entre estos dos personajes en el que el Mamá Grande sería vista, de manera novedosa, como intermediaria del poder patriarcal. 
objeto deseado, pero abyecto, que Ambrosio mantiene encerrado "durante tantos años en aquel rancho de tablones con techo de zinc" (31).

Las concepciones que asocian a la amante y la prostituta con lo puramente erótico llevan a creer que se trata de mujeres con una sexualidad más libre y realizada que la de la esposa. Esto no es cuestionado en ninguno de los dos cuentos, pues en ellos las amantes aparecen como poseedoras de un saber erótico de manera "natural". Por ejemplo, Isabel la Negra es la iniciadora sexual y maestra de los hijos de los amigos de Ambrosio:

[...] no era por ellos que yo hacía lo que hacía sino por mí, [...] para enseñarles que las verdaderas mujeres no son sacos que se dejan impalar contra la cama, que el hombre más macho no es el que enloquece a la mujer sino el que tiene el valor de dejarse enloquecer, enseñándolos a enloquecer conmigo ocultos en mi prostíbulo, donde nadie sabrá que ellos también se han dejado hacer, que ellos han sido masilla entre mis manos, para que entonces puedan, orondos como gallos, enloquecer a las blanquitas, a esas plastas de flan que deben de ser las niñas ricas (32).

Niñas ricas como Liliana en "Las fiebres del Miramar", quien logra alcanzar el placer con su esposo después de que este ha aprendido a mejorar su desempeño sexual con Piedad, "una mujer sin pudor y complaciente que le arrancaba [a Nick] la máscara del puritanismo" (361):

De haber podido hacerlo, Liliana le habría agradecido a Piedad el haberle enseñado a Nick a despertar su sensualidad. Ahora vivían una verdadera luna de miel en vez de fingirla cogiéndose de manos y mirándose como enamorados [...] se retiraban temprano a su cuarto para entregarse de nuevo a sus juegos voluptuosos. Liliana resplandecía como un diamante (364).

Liliana sale victoriosa pues logra el placer sexual que comúnmente está destinado a la amante; ella integra en su actuación una sexualidad gozosa sin dejar a un lado la performance social de la esposa, llegando finalmente a ser dos en una: la decente y la perversa, la santa y la puta. En ese sentido, puede decirse que el personaje consigue desligarse del papel de objeto y se convierte en sujetos con un cuerpo propio ${ }^{7}$.

${ }^{7}$ En su libro La rebelión de las niñas. El Caribe y la “consciencia corporal”, Nadia Celis (2015) desarrolla los conceptos de "cuerpo apropiado" y “cuerpo propio" para referirse 


\section{Oposición e influencia}

Los mundos de las esposas y de las amantes son opuestos pero, al mismo tiempo, se revelan como mutuamente influyentes. Con respecto a la raza a la que son asignados los personajes femeninos, en el cuento de Moreno "constituye un fetiche, un umbral de deseo”, como escribe González (2002: 211). Si la proveniencia afro de la amante atrae sexualmente a Nick, la blancura de la esposa es deseada por Raúl, el hermano de Piedad. En ambos casos, hay una exotización de la diferencia.

Con respecto a la pertenencia de Liliana a una supuesta raza blanca, González (2002) aclara que se trata más bien de una "de mujer mestiza y criolla libre [...] aunque a veces aparezca enmascarada por los valores señoriales heredados de la sociedad esclavista" (205). En primer lugar, habría que aclarar que las palabras "mestizo" y "criollo" tiene variadísimas connotaciones, en Colombia y Latinoamérica. Los criollos, descendientes de europeos pero nacidos en América, fueron los impulsores de la mayoría de los procesos de independencia de las colonias americanas y constituyeron las élites locales. Esta categoría involucra ya un cierto grado de mestizaje, sobre todo si se tiene en cuenta que los relatos de Moreno y Ferré se sitúan en Puerto Rico y el Caribe colombiano, es decir, la América de las plantaciones o Afroamérica. González (2002) habla de "aquellos criollos conformados por mestizos y mulatos libres" (205). Así que los personajes de la élite latinoamericana de estas obras, sobre todo la de Moreno, son en realidad mestizos, y más aún la barranquillera Liliana ${ }^{8}$. Ella debe ser, entonces, mucho más blanca y menos morena que Piedad, aunque probablemente más mestiza que Nick ${ }^{9}$.

a la oposición que existe entre la construcción social del cuerpo, ajena a los sujetos femeninos, y la construcción autónoma de este.

${ }^{8}$ Desde la segunda mitad del siglo XIX hasta las primeras décadas del XX, Barranquilla, al ser puerto marítimo y fluvial que conecta con el interior del territorio nacional y el exterior, se convierte en una importante entrada al país de inmigrantes extranjeros como sirios, palestinos, libaneses, franceses, alemanes, judíos, norteamericanos, italianos, chinos y japoneses, entre otros, muchos de los cuales se asientan en la ciudad.

${ }_{9}$ Esto último debe también ser tomado en consideración, pues en un contexto transnacional, para el estadounidense Nick, Liliana ya es una mujer "exótica" por su procedencia "latina". 
En cuanto a Piedad, nunca se habla directamente de su raza, pero todo en el cuento apunta a que es mucho más oscura que Liliana. Su retrato es el de una buena salvaje, simple, natural, ingenua, indefensa, humilde, que ama sinceramente a Nick y que quiere una mejor vida para ella y su familia. Ente pasivo al que se le imponen las circunstancias, aprovecha lo que se le presenta -el amante "gringo" adinerado- pero, al mismo tiempo, sufre las agresiones sin hacer nada para remediarlo. Es descrita como un "pajarito asustado" (363), que fue violada por su hermano a los 12 años, que llora y suplica a Nick que no la deje y que sufre nuevamente la violencia de Raúl cuando este le quita "los diez mil pesos que Nick le había dado como regalo de despedida" (364).

A esta Galatea mulata, Nick-Pigmaleón decide enseñarle "buenos modales": "a sentarse sin abrir las piernas, a utilizar los cubiertos como es debido y a extirpar de su vocabulario las frases vulgares [...]. [Piedad] ya no se ponía pachulí, ni el estridente rojo ${ }^{10}$ de labios de antes" (361-362). La muchacha comienza también a preguntarse "confusamente si sus apetitos carnales serían del agrado de Nick. [...] Piedad estaba perpleja. Por un lado Nick la incitaba a volverse distinguida, es decir lánguida y delicada, y por el otro quería verla lujuriante y siempre disponible" (363). Así que una vez introducida a la normatividad, fuera de su paraíso originario, Piedad abandona su estado edénico de ingenuidad y pureza, empieza a distinguir el bien y el mal y se introduce en el mundo de la culpa y la vergüenza: se convierte en un ser moral. No podemos dejar de notar la esencialización de las culturas no occidentales que se opera aquí, que las caracteriza como irracionales, pre-simbólicas. Además, esto afirmaría que Piedad, antes de conocer a Nick, no estaba sujeta a la moral del poder, como si ser violada por su hermano, pertenecer a una familia numerosa y ser sirvienta de un balneario de clase alta no la ubicara ya en pleno centro de los conflictos de género, clase y raza.

González (2002) comenta que en la obra de Moreno la subversión viene casi siempre del lado de las culturas marginalizadas: "Varios cuentos se remontan a un Caribe ensoñado, atravesado por las creencias afroantillanas animistas, que se forjan en el mundo colonial hispánico como formación de

${ }^{10}$ El rojo estridente sería una marca de clase y raza. Aquí aparece portado por Piedad, y en Ferré remite a la negrura o negritud de Isabel la Negra cuyos tacones y uñas son de este color. 
unas culturas de resistencia" (204). Pero esa resistencia no le sirve de nada a Piedad; en cambio, la que finalmente triunfa gracias a este elemento es Liliana, quien aprende de la otra, por intermedio de su esposo, la liberación sexual. Según esta interpretación, ella, perteneciente a la élite blanca, incorporaría entonces ciertos rasgos de esta negritud esencializada.

Tampoco le sirve de mucho a Piedad tener un trabajo porque este no constituye una liberación de la triple opresión a la que está sometida: ser mujer, negra y pobre. En el balneario donde labora, los hombres como Nick la acosan con la mirada -y de seguro también verbal y físicamente-. El escaso dinero que gana lo utiliza para sobrevivir, entregándoselo a su madre para alimentar a sus quince hermanos. Así que su trabajo no redunda en una ostensible mejora de su calidad de vida, pues no le sirve para lograr una autonomía económica ni a una realización de sí.

Aunque puede también pensarse que Piedad logra al final ciertos beneficios: aprende a leer y a escribir, deja de ser la sirvienta del balneario para, por un momento, "subir de categoría" al ser la "querida" de un millonario. Sin embargo, el relato no desarrolla más su infortunada historia, como si las mujeres afroamericanas de clase baja no tuvieran posibilidades de salir adelante. No es este un panorama feminista que reconozca la diversidad de la experiencia femenina. Se opera, en cambio, como mencionamos, una invisibilización del sujeto femenino subordinado, lo que es prueba de cierto elitismo recurrente en la obra de Moreno. Sin embargo, las lectoras del cuento podríamos imaginar un final más feliz para este personaje, pensar que su experiencia con Nick la lleva a cuestionarse acerca del amor idealizado y rechazar un futuro como amante de un hombre adinerado.

Pero esto no es así. En "Las fiebres del Miramar" solo la mujer burguesa, Liliana, se alza como la heroína que se aleja feliz en un barco a los Estados Unidos, con su marido recuperado y un futuro lleno de esperanzas. Este personaje encarnaría el punto de vista del feminismo blanco hegemónico en manos de mujeres privilegiadas y letradas que, según bell hooks (s.f.), utilizan la lucha feminista para ascender en la escala socioeconómica, sin modificar el sistema sexista existente. Podría concluirse que, desde esta perspectiva, Piedad es "sacrificada" en el cuento para que Liliana triunfe.

En el relato de Ferré el conflicto racial es mucho más evidente. La procedencia étnica de Isabel Luberza es subrayada varias veces: se describe su piel "de raso de novia, de leche de cal" que se derrama "por el escote y por los 
brazos" (39). Ella sabe que su blancura es un bien preciado, su "pedigree"; y sin embargo, se arriesga a perderla, a ponerse más morena con el sol y despertar los comentarios en su entorno: “[...] has visto lo amelcochadita que se está poniendo sutanita con la edad. La pobre, dicen que eso requinta, que al que tiene raja siempre le sale al final" (39).

La negrura de Isabel la Negra también es una y otra vez resaltada: "Isabel la Perla Negra del Sur, la Reina de Saba, the Queen of Chiva, la Chivas Rigal, la Tongolele, la Salomé” (25). De la misma manera que Isabel Luberza quiere ennegrecerse, Isabel la Negra desea usar el polvo de Chant d'Aromes de su rival para blanquear sus pechos y ponerse sus joyas con el propósito de sustituir a la esposa (28). Gilard (1997) afirma que en el relato la tensión entre las razas es resuelta de una forma extrema "al oponer primero y al trastrocar luego a la meretriz negra y a la esposa blanca” (120).

Isabel la Negra es, al igual que Piedad, una trabajadora, en su caso, una prostituta. Su ascensión en la escala económica es marcada a lo largo del relato. Cuando Ambrosio vivía, dependía de él y debía hacer lo que este le decía, incluyendo tener relaciones sexuales con los "niñitos ricos" (31). Pero esto cambia con su muerte: se convierte en "una self-made woman, que había alcanzado en el pueblo un estatus envidiable, a los ojos de muchas de esas mujeres de sociedad [...] que no tienen dinero ni para darse su viajecito a Europa al año como yo me lo doy" (30). Aquí también se evidencia el deseo de ser como la esposa, una mujer públicamente prestigiosa.

Pero estas aspiraciones de ser como la otra son inauténticas en la medida en que surgen de la cosificación que se ha ejercido sobre ellas y que ellas reproducen. Ninguna logra considerar a su rival como un sujeto autónomo que piensa y siente, sino que la ve como objeto idealizado. Lo que les interesa a cada una es la pose, la imagen que desde fuera la otra refleja: la esposa oficial sentada al balcón con un vestido de lamé plateado, o la amante negra tongoneando sus nalgas. No llegan nunca a ver más allá de estas apariencias, no reconocen el sufrimiento en la otra, el dolor, las dificultades, la violencia sufrida. Esposa y amante le niegan a su oponente una subjetividad compleja, repitiendo las ideas y juicios de la sociedad sexista, clasista y racista en que habitan. A lo largo del cuento son incapaces de "meterse en el cuerpo de la otra".

Al final de las historias, los dos cuentos proponen soluciones a la escisión de los personajes femeninos. En el caso de "Cuando las mujeres quieren a los hombres", con la transformación de la una en la otra se resolvería la falta 
de reconocimiento mutuo. Podría pensarse que se trata de una especie de castigo: ahora sí van a saber qué es vivir, sentir y ser tratada como la otra. Solo así podrán comprender a su antagonista, quien dejará de ser enemiga para convertirse en hermana. Así, al final Ferré afirmaría que para que haya una verdadera comprensión, debemos "ponernos en los zapatos del otro"; únicamente de esta manera puede haber una verdadera comunión entre los individuos.

Según otra interpretación posible del cuento, no se trataría de dos mujeres distintas sino de una sola, pero fragmentada, con un conflicto interior entre dos de las facetas de su personalidad. Como dijimos en un principio, creemos que ambas opciones no riñen completamente pues se basan en la idea de que las mujeres reales están siempre confrontadas a representar a un ideal abstracto que nunca puede llegar a concretarse. Ya Beauvoir (1980) explicaba que la idea tradicional de la mujer es dual: "No hay ninguna imagen de mujer que no genere inmediatamente su imagen inversa: es la Vida y la Muerte, la Naturaleza y el Artificio, la Luz y la Noche" (277). Presentaremos ahora otras consideraciones acerca del posible desdoblamiento de un solo ser del cuento de Ferré que nos conducirán a la segunda propuesta hermenéutica de nuestro ensayo.

Según Lagos-Pope (1985), Isabel Luberza e Isabel la Negra encarnarían a un yo falto de unidad, alienado por la división "entre lo que se es y lo que se debe ser, entre la autenticidad y la conformidad con las convenciones sociales" (736). También Balseiro (1997) afirma que en el cuento se subraya el problema de la división del yo "cuya alienación puede ser superada a través de la unificación de sus fragmentos. Los dos personajes serían partes complementarias de la misma mujer, y solo por medio de la integración de sus respectivas personalidades emergería un ser humano entero" (3, mi traducción) ${ }^{11}$. Por su parte, Gutiérrez (1992) propone que el cuento presenta un itinerario hacia la unidad en el que, sin embargo, no hay fusión sino metamorfosis de Isabel Luberza en Isabel la Negra ${ }^{12}$.

11 "whose alienation can only be overcome through the unification of its fragments. Isabel la Negra and Isabel Luberza are complementary parts of the same woman, and only through the integration of their respective personalities does a whole human being emerge" (Balseiro, 1997, 3).

${ }^{12}$ Pero según Gutiérrez, esta Isabel la Negra final es en realidad una nueva mujer pues ha integrado en su cuerpo ciertas características de la esposa, por ejemplo, su blancura. 
Lo que nos llama la atención de estas interpretaciones es que mantienen la idea de que el ser debe ser idealmente unitario, coherente e integrado, sin contradicciones. Pensar en la escena final como una metamorfosis habla del deseo de que la horrible oruga se convierta finalmente en una hermosa mariposa, es decir, una nueva versión de la mujer ideal de la que se venía huyendo. Esta concepción no considera la posibilidad de que las identidades, más que fijas y estables, son rizomáticas y fragmentadas, mucho más en nuestros contextos multiculturales y decoloniales. Por ello, preferimos leer el cuento desde una postura que, más que juzgar lo que logran o no los personajes femeninos -el resultado final- como si fuera algo concluyente, analice los procesos que se producen en la construcción constante de la subjetividad.

Esta forma de comprender el relato toma en cuenta el que sea fantástico, pues como lo manifestamos, la duda debe primar. No por nada el mismo lenguaje empleado juega con la ambigüedad en cuanto a la identidad de la narradora. Por ejemplo, en una misma frase podemos ver un cambio de sujeto: "Isabel La Negra preparando su cuerpo para recibir el semen de los niños ricos, de los hijos de los patrones amigos tuyos que entraban todas las noches en mi casucha" (24; énfasis agregado). Además de este juego y ambigüedad en cuanto a la identidad de quien habla, se hace presente un "nosotras", y a veces un "ellas" que terminan por confundir, a propósito, toda idea de enunciación coherente. Si bien es claro que una se convierte en la otra, resulta imposible saber quién sobrevive al final: ambas o ninguna. Hay, pues, un deslizamiento identitario en la que una afecta a la otra, lo que constituye una nueva forma de ver las relaciones entre las distintas manifestaciones del ser mujer.

\section{El deslizamiento identitario: La sororidad}

Sedgwick (1985) plantea que en algunos triángulos amorosos de la literatura inglesa del siglo XIX en que se suponía que dos hombres competían por una mujer, el deseo homosocial masculino era más poderoso. Los dos rivales utilizaban el cuerpo de la mujer como un recipiente que los conectaba con el otro de su mismo sexo, pues era con este que preferían tener relaciones. Deleuze (1970) llega incluso a plantear que la homosexualidad es la verdad 
del amor, es decir, que el amor heterosexual es en realidad una homosexualidad encubierta.

Si leemos los cuentos de Moreno y de Ferré desde esta óptica, vemos que en ellos hay claramente una relación fantasiosa entre esposas y amantes, un intercambio entre ellas a través de los hombres compartidos. Esto los convierte a ellos en instrumentos o prótesis, lo que invierte la relación existente en las sociedades patriarcales entre hombres y mujeres, siendo estas las que normalmente cumplen con el papel de objetos de cambio. El vínculo que importa en los relatos es en realidad el que se teje entre ellas; los hombres resultan ser canales para que puedan jugar a ser la otra y, finalmente, para que lleguen a despegarse del rol que les han impuesto.

En el cuento de Ferré se habla a veces en plural, de un nosotras para mostrar que la relación amorosa es entre ellas dos, una y su alterego, una y otra que estaban tal vez dentro de la misma mujer y que tenían el deseo de reconciliarse al final, no con Ambrosio, sino con ellas mismas. A pesar de que siguen poniendo de excusa la pasión por él, es claro que existe entre ambas un deseo escondido:

Nosotras, tu querida y tu mujer, siempre hemos sabido que debajo de cada dama de sociedad se oculta una prostituta. Se les nota en la manera lenta que tienen de cruzar una pierna sobre la otra, rozándose los muslos con la seda de la entrepierna. Se les nota en la manera en que se aburren de los hombres [...]. Se les nota en la manera en que van saltando de hombre en hombre sobre las patas de sus pestañas, ocultando enjambres de luces verdes y azules en el fondo de sus vaginas. Porque nosotras siempre hemos sabido que cada prostituta es una dama en potencia [...], anegada en esa nostalgia del sonido que hace la losa cuando manos invisibles ponen la mesa. Porque nosotras, Isabel Luberza e Isabel la Negra, en nuestra pasión por ti, Ambrosio, desde el comienzo de los siglos, nos habíamos estado acercando, nos habíamos estado santificando la una a la otra sin darnos cuenta, purificándonos de todo aquello que nos definía, a una como prostituta y a otra como dama de sociedad (23).

A través del tono sensual del texto, queda demostrado que lo importante es la cercanía con ese sexo que no es uno, parafraseando a Irigaray. Esto se entiende con alusiones como las luces en el fondo de las vaginas y el frote de los labios genitales al cerrar las piernas, lo que remite a una relación lésbica auto u homoerótica. 
En cuanto a la relación de cercanía entre los personajes femeninos del relato de Moreno, ya habíamos comentado que Liliana asimila las artes amatorias de Piedad, lo que puede ser entendido como una aspiración a ser como ella, e incluso a estar con ella. Piedad, por su parte, también comienza a parecerse a Liliana, no solo al vestirse y al hablar como una mujer de la élite, sino que "había comenzado de repente a soñar" (362), a desplegar nuevas ilusiones: tener una relación estable, así fuera con un hombre casado, y viajar a los Estados Unidos. Todo esto la acerca mucho más a Liliana. Piedad también comienza a hacerse preguntas y hacérselas a Nick, siendo más consciente de su rol dentro de la relación y cuestionándolo. Deja así de ser objeto y accede a cierto estatus como sujeto, al igual que Liliana, quien no es ya la única pensante.

Allí radica la profunda subversión de los cuentos. El que dos mujeres se gusten y descubran a través de la otra nuevas posibilidades identitarias representa, sin duda, una amenaza contra los privilegios de la masculinidad hegemónica y una ruptura abierta con la heteronormatividad. Las mujeres ya no estarían obligadas a competir entre ellas, sino que se vislumbra la construcción de nuevas y diferentes maneras de actuar el ser mujeres, ya no solo los dos roles que las oponen y las apartan de sí mismas.

La insistencia y celebración de la rivalidad femenina naturalizada invisibiliza el hecho de que esta es una consecuencia de la misoginia del pensamiento masculinista. En América Latina, a través de todo tipo de literatura, se ha reforzado la idea que existen dos papeles femeninos aparentemente irreconciliables. En la literatura patriarcal canónica del Caribe, como Cien años de soledad de Gabriel García Márquez y La guaracha del Macho Camacho de Luis Rafael Sánchez, por ejemplo, se tiene por un lado a las esposas agraviadas (Fernanda del Carpio y Graciela Alcántara) y por otro a las alegres amantes (Petra Cotes y la China Hereje). También la cultura popular - las canciones, la crónica roja, las telenovelas- animan y espectacularizan los antagonismos entre las mujeres. Así que es reconstituyente encontrarse obras literarias escritas por mujeres que, en vez de fortalecer estos discursos y comportamientos insolidarios, los cuestionan e intentan subvertirlos ${ }^{13}$.

${ }^{13}$ Cfr. por ejemplo, Ortega y Ortega (2015). 
Diferentes corrientes feministas han reivindicado el término sororidad (del latín sor, hermana), que se refiere a la hermandad entre mujeres. bell hooks explica que se trata de una solidaridad no simplemente referida a que varias mujeres compartan la misma situación de sufrimiento y opresión, que generen una simpatía recíproca y que tomen consciencia de ello, asumiendo la condición de víctima universal; consiste, en cambio, en operar una transformación, constituir una causa común y llegar a un compromiso político (en Ferrarese, 2012: 223).

Según Ferrarese (2012), para hooks la sororidad implica que cada mujer vuelva sobre sí misma, en dos sentidos. Primero, debe haber un autocuestionamiento que la aleje de la retórica victimaria, una aceptación de que puede ser ella también herramienta de su propia dominación y de la opresión de otras mujeres: reconocer a la enemiga interior que cada una lleva dentro y aceptar la responsabilidad de esta carga. Segundo, se debe operar una modificación de las relaciones intersubjetivas. Estos procesos necesitan entonces del amor, concebido también de dos formas: como amor propio y amor a las otras. El primero remite al empoderamiento o empowerment, y es la condición previa y necesaria para el segundo, al que la sororidad remite propiamente. Este segundo tipo de amor se entiende como capacidad de empatizar con la otra, como la elección de ponerse en su lugar, de percibir los puntos ciegos de nuestras posturas personales y compromisos políticos. Se trata entonces de reconocer a las otras y respetarlas, en vez de despreciarlas, discriminarlas o descalificarlas.

\section{Conclusiones}

En los cuentos de nuestro análisis hay una visibilización crítica de los binarismos, de manera que se complejizan las relaciones de poder entre los agentes. En la abierta exposición de los contrarios, en el desenmascaramiento de los estereotipos, se da un cuestionamiento de las actuaciones propias y ajenas que se ejecutan de manera mecánica. Solo cuando aparece la otra (Piedad/Isabel la Negra), las señoras advierten su subordinación con respecto a los maridos, quienes les imponen una amante, lo que les genera enojo y frustración. Esa impotencia las hace sospechar que los "privilegios" de su papel de esposas no son tales. Algo similar sucede con las 
amantes que, al compararse con las esposas, se interrogan acerca de su rol como subordinadas. Así, cada una influye sobre la forma en que la otra se percibe a sí misma.

Aunque unas consiguen enriquecerse más que otras -como en el caso de Liliana, cuya ganancia parece superar a la de Piedad-, sin duda se presenta un intercambio de saberes, hecho de forma consciente o no. Aquí estaríamos comprendiendo que la sororidad es diversa, plural y no exenta de desigualdades, no es un paraíso donde todas están de acuerdo y consiguen lo que quieren. Lo que sí está en la agenda es la posición contrahegemónica que cuestiona los pares de representación clásica de las mujeres: una solidaridad conducente a un acto que modifique la enemistad y la agresión entre mujeres, propias de la heteronormatividad, que las convierta en hermanas en armas, más allá de las fronteras de raza y clase. Y en los personajes femeninos de Ferré y Moreno hemos visto que se crean alianzas insospechadas: en el encuentro de las dos mujeres, o de las dos facetas de la misma mujer, se construye un yo más complejo que valora la pluralidad.

Hay un acontecimiento de "Las fiebres del Miramar" que aún no hemos considerado: la herida que Liliana le causa a Raúl en su ojo cuando este la fisgoneaba. Es evidente que ella contrapone al discurso patriarcal el discurso clasista, para salirse con la suya: echa mano de las ventajas que le proporcionan pertenecer a la burguesía y anula a Raúl. Pero podría pensarse también que Liliana está ejecutando la venganza contra Raúl en nombre de Piedad: él abusó sexualmente de su hermana, y Liliana la desagravia al penetrar el ojo de este violador, introduciendo en él un alfiler, haciéndolo sangrar y dejándolo marcado de por vida. Este acto podría ser entendido como un favor o servicio que le presta Liliana a Piedad, que hace que ya no esté sola e indefensa, sino que haya encontrado una aliada inesperada. Esto puede ser entendido como el surgimiento de una colectividad, de una comunidad de mujeres con distintas características que se cuidan las unas a las otras. Relacionamos este episodio con la ética del cuidado que señala Celis (2010: 569), un código moral femenino en el que se politizan los vínculos afectivos. Siguiendo a Irigaray, Celis (2010) también subraya "el potencial político que subyace en el carácter intersubjetivo de la formación del yo femenino, y en la ética de la solidaridad mutua" (569).

El gesto de Liliana con el alfiler también puede ser leído como un performance trangresor y queer, pues un gesto plenamente femenino, como lo 
es quitarse el alfiler del primoroso sombrero, se convierte en una estocada fálica en el ojo del enemigo. Ese ojo que precisamente es un instrumento masculino de control, con el que Raúl quería verla desnuda sin su consentimiento, y que seguramente luego gozaría al verla debatirse mientras la violaba, es penetrado aquí por Liliana de manera violenta. Recordemos que la vista es el sentido por excelencia de la lascivia masculina, herramienta de la sexualización de las mujeres, prolongación del pene, falo ocular.

Llegamos así al final de nuestra dual propuesta interpretativa de estos dos cuentos escritos por mujeres del Caribe hispánico. Dejamos las posibilidades abiertas para que la relación entre los personajes femeninos de los relatos pueda ser entendida como antagonismo o como sororidad. Queremos ver en estas contradicciones no una falla, sino una oportunidad para repensar las subjetividades en términos menos uniformes y más como devenires sin fin. Observamos también que es necesario que se sigan realizando estudios comparativos entre las obras de Ferré, Moreno y autoras latinoamericanas como Clarice Lispector, María Luisa Bombal, Silvina Ocampo, Luisa Valenzuela, y narradoras del Caribe como Fanny Buitrago, Ana Lydia Vega, Mayra Santos-Febres, Jamaica Kincaid y Maryse Condé, por citar algunas. De esta manera se logrará seguir ensanchando el círculo de hermanas que empuñan el arma de la escritura.

\section{Referencias}

Balseiro, I. (1997, otoño). Through the Looking Glass, Darkly: Rosario Ferré's "Cuando las mujeres quieren a los hombres". Afro-Hispanic Review, 16(2), 3-9.

Beauvoir, S. de. (1980 [1949]). El segundo sexo. Buenos Aires: Siglo XX.

Celis, N. (2010, primavera). "Algo tan feo" en la vida de dos señoras bien: Los relatos de formación de Rosario Ferré y Marvel Moreno. Revista canadiense de Estudios hispánicos, 34(3), 559-579.

Celis, N. (2015). La rebelión de las niñas. El Caribe y la consciencia corporal. Iberoamericana/Vervuert: Madrid/Frankfurt am Main.

Deleuze, G. (1970). Los signos. Proust y los signos. Barcelona: Anagrama.

Ferrarese, E. (2012). Bell hooks et le politique. La lutte, la souffrance et l'amour. Cahiers du Genre, 1(52), 219-240. Disponible en de www.cairn.info/revuecahiers-du-genre-2012-1-page-219.htm.

Ferré, R. (2000 [1976]). Papeles de Pandora. New York: Vintage. 
Gilard, J. (1997). Elite, femineidad y mestizaje en el Caribe: Los cuentos de Rosario Ferré y Marvel Moreno. En Quaderni del Dipartimento di lingue e letterature neolatine dell'Università di Bergamo (113-125). Bérgamo: Universidad de Bérgamo.

Gontovnik, M. (2014, 3 de noviembre). El país de los tormentos. El Heraldo. Disponible en http://www.elheraldo.co/columnas-de-opinion/el-pais-delos-tormentos-172442

González, S. (2002). Marvel Moreno: Fronteras narrativas. En Constelaciones y redes. Literatura y crítica cultural en tiempos de turbulencia (202-215). Bogotá: Pontificia Universidad Javeriana.

Gutiérrez, M. (1992, invierno). Rosario Ferré y el itinerario del deseo: Un estudio lacaniano de "Cuando las mujeres quieren a los hombres". Revista Canadiense de Estudios Hispánicos 16(2), 203-217.

hooks, bell. (s.f./200o). El feminismo es para todos [Feminism is for Everybody]. Traducción de Camila Rebolledo Krefft. Disponible en http://documents.mx/ documents/bell-hooks-feminismo-es-de-todos-traduccion.html

Lagarde, M. (2001). Claves feministas para la negociación del amor. Managua: Puntos de encuentro. . (2003 [1990]). Los cautiverios de las mujeres. Madresposas, monjas, putas, presas y locas. México: Universidad Nacional Autónoma de México.

Lagos-Pope, M.I. (1985, julio-diciembre). Sumisión y rebeldía: El doble o la representacion de la alienacion femenina en narraciones de Marta Brunet y Rosario Ferré. Revista Iberoamericana, 132-133, 731-749.

Moreno, M. (1995, junio 25). Las fiebres del Miramar. Lecturas dominicales de El Tiempo, 6-7; Quimera, 31-132, 48-50.

Moreno, M. (2001). Cuentos completos. Bogotá: Norma.

Ortega González-Rubio, M.E. y Ortega González-Rubio, M. (2015). Imaginar a Ángela Vicario: Una relectura de Crónica de una muerte anunciada, de Gabriel García Márquez. En O. Araújo Fontalvo (Ed.), El legado de Macondo (159-178). Barranquilla: Universidad del Norte.

Sedgwick, E. (1985). Between men. English Literature and Male Homosocial Desire. New York: Columbia University Press.

Simonovis, S. (2010). Isabel Luberza Oppenheimer: variaciones de una misma plena. Tinkuy. Boletín de investigación y debate, 13, 65-75.

Todorov, T. (2001(1980]). Introducción a la literatura fantástica. México: Premia. 